\title{
Processamento do milho grão sobre desempenho e saúde ruminal de cordeiro
}

\author{
Processing of corn grain on feedlot and rumen health in lambs
}

\author{
Letícia Silva Oliveira ${ }^{\mathrm{I}}$ Madeline Rezende Mazon $^{\mathrm{I}^{*}}$ Roberta Ferreira Carvalho ${ }^{\mathrm{I}}$ \\ Domingos Marcelo Cenachi Pesce ${ }^{I I}$ Saulo da Luz e Silva ${ }^{I}$ José Carlos Machado Nogueira Filho ${ }^{I}$ \\ Sarita Bonagurio Gallo ${ }^{I}$ Paulo Roberto Leme ${ }^{\mathrm{I}}$
}

\section{RESUMO}

Vinte e dois cordeiros machos não castrados, Dorper $x$ Santa Inês, com aproximadamente 90 dias de idade e peso vivo médio inicial de 27,0 $44,4 \mathrm{~kg}$, foram alimentados com uma dieta com elevada proporção de concentrado com $20 \%$ de pelete proteico-mineral (Grano Entero ${ }^{\circledR}$ ), $5 \%$ de feno de capim coastcross e $75 \%$ de milho, na forma de milho grão inteiro (MGI), milho grão moído (MGM) ou milho grão úmido (MGU), para avaliação de desempenho no confinamento por um periodo de 14 dias de adaptação às dietas e às instalações e de 65 dias de confinamento. Em seguida, os animais foram abatidos com peso vivo médio final

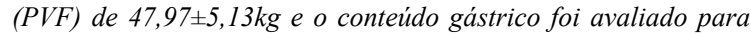
quantificação de protozoários, e foi realizada avaliação papilar. $O$ delineamento experimental foi o de blocos casualizados. Não houve diferença entre os tratamentos $(P>0,05)$ quanto ao ganho de peso médio diário, eficiência alimentar, ingestão diária de matéria seca, características da carcaça e da carne. Os animais tratados com MGI tiveram maior conteúdo gástrico, menor $\mathrm{pH}$ ruminal, maior AP (\% da superficie de absorção) e maior área papilar em comparação com os outros tratamentos. Os animais tratados com MGI tiveram melhores resultados para o peso final, mas para os demais parametros estudados não foi observada diferença.

Palavras-chave: protozoários, ruminite, abscessos hepáticos, $p H$ fecal, pH ruminal, eficiência alimentar.

\section{ABSTRACT}

Twenty-two males not neutered, Dorper $x$ St. Agnes, with approximately 90 days of age and average live weight of $27.0 \pm 4.4 \mathrm{~kg}$ were fed with a diet wich contained high concentrate with $20 \%$ protein pellet-mineral (Grano Entero ${ }^{\circledR}$ ), 5\% grass hay coast-cross and $75 \%$ corn in the form of whole kernel corn (MGI), ground corn grain (MGM) or high moisture corn (MGU) for performance evaluation in confinement for a period of 14 days of adaptation to the diets and facilities and 65 days of confinement. Then the animals were slaughtered at average final weight (PVF) of $47.97 \pm 5.13 \mathrm{~kg}$ and gastric content was evaluated for quantification of protozoa, and a papillary review was conducted. The experimental design was in randomized blocks. There was no difference between treatments $(P>0.05)$ for average daily weight gain, feed efficiency, daily dry matter intake, carcass characteristics and meat. MGI-treated animals had higher gastric contents, the lower ruminal $\mathrm{pH}$ greater AP (\% of surface absorption) and the larger papillary area was compared with other treatments. Animals treated with MGI had better results for the final weight gain, but for the other parameters studied, no difference was observed.

Key words: fecal $\mathrm{pH}$, feed efficiency, liver abscesses, protozoa, ruminal $\mathrm{pH}$, ruminate.

\section{INTRODUÇÃO}

Em sistemas intensivos de produção de carne, geralmente a utilização de dietas de alto concentrado, a base de grãos de cereais, é vantajosa quando se considera o custo por megacaloria de energia líquida de manutenção ou energia líquida de ganho. Por essa razão e visando maior eficiência alimentar dos animais confinados, os produtores de ovinos utilizam dietas que contenham grãos que sejam rapidamente fermentáveis no rúmen, para maximizar a ingestão de energia (BROWN et al., 2006; STEELE et al., 2009).

Com este enfoque, o processamento do milho torna-se uma alternativa interessante. Um dos benefícios seria o aumento da digestibilidade ruminal

'Faculdade de Zootecnia e Engenharia de Alimentos (FZEA), Universidade de São Paulo (USP), 13635-900, Pirassununga, SP, Brasil.

E-mail: mad-mazon@usp.br. *Autor para correspondência.

"Pontifícia Universidade Católica de Minas Gerais (PUC-MINAS), campus, Poços de Caldas, MG, Brasil. 
do amido, proporcionando mais energia disponível para o desenvolvimento da população microbiana, o que resulta em maior produção de ácidos graxos de cadeia curta - AGCC (PASSINI et al., 2003).

No entanto, com dietas de alto grão de cereal, aumenta a possibilidade de ocorrer acidose ruminal. As manifestações clínicas da acidose metabólica incluem a depressão no consumo de ração, laminite, abscessos de fígado nos casos crônicos, ruminite e alterações extensas da microbiota ruminal e seus produtos da fermentação, além de lesões na mucosa do rúmen (RESENDE JÚNIOR et al., 2006; STEELE et al., 2009).

Dessa forma, objetivou-se comparar o efeito do processamento do milho através de dietas, com elevada proporção de concentrado, contendo milho inteiro ou processado de diferentes formas (grão seco moído ou úmido) sobre o desempenho, a incidência de ruminites, morfometria das papilas ruminais, $\mathrm{pH}$, conteúdo ruminal, presença de abscessos hepáticos e quantificação de protozoários.

\section{MATERIAL E MÉTODOS}

O experimento foi desenvolvido no Departamento de Zootecnia da Faculdade de Zootecnia e Engenharia de Alimentos da Universidade de São Paulo, localizada no Município de Pirassununga - SP. Utilizaram-se 22 cordeiros
Dorper x Santa Inês, machos não castrados, com idade média de 90 dias e peso vivo médio inicial de $27,07 \pm 4,36 \mathrm{~kg}$. Foram submetidos a 14 dias de adaptação às dietas e às instalações e o período de confinamento de 65 dias, em baias individuais, com as dietas experimentais contendo $20 \%$ de pelete protéico-mineral (Grano Entero ${ }^{\circledR}$ ), $5 \%$ de feno de capim coast-cross e $75 \%$ de milho, e compararam-se três diferentes formas do milho: milho grão inteiro (MGI), milho grão moído (MGM) e milho grão úmido (MGU) (Tabela 1).

Foram utilizados grãos de milho DOW 2B707, de textura semi-dura, tratados com inseticida Cruiser $^{\circledR} 350 \mathrm{FS}$, com a finalidade de proteção do grão durante a estocagem. O grão úmido de milho foi ensilado em tubo de lona plástica aos 109 dias, após semeadura, com a colheita dos grãos com teor de umidade de $40 \%$, na lavoura. A moagem utilizada nos grãos úmidos de milho, antes do processo de ensilagem, foi realizada utilizando-se o equipamento Silotress Poetter, modelo OP20, série 00200. A abertura do silo contendo milho grão úmido ocorreu após seis meses do processo de ensilagem (CAETANO, 2012). Em relação à descrição física do grão de milho, o diâmetro geométrico médio foi de $5,84 \mathrm{~mm}$ para o milho grão úmido, $1,30 \mathrm{~mm}$ para o milho grão moído e $5,99 \mathrm{~mm}$ para o milho grão inteiro. A moagem dos grãos secos foi realizada em peneira de 3mm (CAETANO, 2012).

Tabela 1 - Composição das dietas experimentais, expressa na matéria seca.

\begin{tabular}{|c|c|c|c|}
\hline \multirow{2}{*}{ Ingredientes (\%) } & \multirow[b]{2}{*}{ MGI } & \multirow[b]{2}{*}{ MGM } & \multirow[b]{2}{*}{ MGU } \\
\hline & & & \\
\hline Milho grão inteiro & 75 & - & - \\
\hline Milho grão moído & - & 75 & - \\
\hline Milho grão úmido & - & - & 75 \\
\hline Pelete proteico- mineral ${ }^{1}$ & 20 & 20 & 20 \\
\hline Feno & 5 & 5 & 5 \\
\hline \multicolumn{4}{|l|}{ Nutrientes $(\%)$} \\
\hline Matéria Mineral (MM) & 7,19 & 7,27 & 7,29 \\
\hline Proteína Bruta (PB) & 16,85 & 16,57 & 15,37 \\
\hline Extrato Etéreo (EE) & 4,20 & 5,05 & 5,15 \\
\hline Extrato Não Nitrogenado (ENN) & 69,20 & 68,31 & 71,22 \\
\hline Fibra em Detergente Ácido (FDA) & 8,84 & 7,38 & 5,84 \\
\hline Fibra em Detergente Neutro (FDN) & 17,99 & 18,29 & 12,18 \\
\hline Nutrientes Dig. Totais ${ }^{2}(\mathrm{NDT})$ & 77,19 & 77,74 & 78,93 \\
\hline Cálcio & 0,99 & 1,00 & 1,01 \\
\hline Fosforo & 0,39 & 0,39 & 0,39 \\
\hline
\end{tabular}

${ }^{1}$ Nome comercial é Grano Inteiro da Empresa Nutron Alimentos. Valores de composição bromatologica $\mathrm{MS}=91,20 \%$; $\mathrm{MM}=29,80 \%$; $\mathrm{PB}=42,69 \% ; \mathrm{EE}=4,23 \% ; \mathrm{ENN}=26,17 \% ; \mathrm{FDA}=11,47 \% ; \mathrm{FDN}=25,13 \%$.

${ }^{2}$ Valores estimados por meio da equação: \%NDT $=40,2625+0,1969 \% \mathrm{~PB}+0,4228 \% \mathrm{ENN}+1,1903 \% \mathrm{EE} 0,1379 \% \mathrm{FB}(\mathrm{KEARL}, 1982)$. 
A dieta completa foi fornecida uma vez ao dia, pela manhã e à vontade, e ajustada diariamente, para haver uma sobra de $10 \%$ da quantidade oferecida, portanto, o alimento ofertado e a sobra foram pesados individualmente e diariamente. Os animais tinham acesso à água à vontade. Os cordeiros receberam antihelmínticos na fase de adaptação experimental.

Foram realizadas medições semanais do $\mathrm{pH}$ fecal. Utilizaram-se amostras de $20 \mathrm{~g}$ de fezes frescas, coletadas diretamente do reto do animal, acrescidas de $80 \mathrm{ml}$ de água destilada (GOMIDE et al., 2004, adaptado). Após a homogeneização e a completa diluição das fezes, o pH das amostras foi aferido. A cada 14 dias, os animais eram pesados, sem jejum, para determinar o ganho médio diário (GMD) e, no último dia de confinamento, para determinar o peso vivo final (PVF).

Ao final do período experimental, os cordeiros foram abatidos, com jejum de 16 horas, e seguiram-se os padrões adotados no Matadouro-Escola da Coordenadoria do Campus da USP em Pirassununga. A sequência de abate foi: atordoamento por uso de pistola de dardo cativo, sangria, retirada do couro, cabeças, patas e vísceras, com obtenção final da carcaça.

Após o abate, os fígados foram classificados de acordo com a severidade dos abscessos (AH) em escala de 0 a 3 (BRINK et al., 1990). De acordo com esta classificação, os fígados sem abscessos receberam nota 0 , os fígados com um ou dois abscessos menores que $2,5 \mathrm{~cm}$ de diâmetro ou que apresentem cicatrizes de abscessos receberam nota $\mathrm{A}-=1$, os fígados com dois a quatro abscessos ativos menores que $2,5 \mathrm{~cm}$ de diâmetro recebem nota $\mathrm{A}=2 \mathrm{e}$ os fígados com um ou mais abscessos maiores que $2,5 \mathrm{~cm}$ de diâmetro e porções do diafragma aderido à sua superfície receberam nota $\mathrm{A}+=3$.

Os rúmen, retículo, omaso e abomaso foram pesados cheios logo após a evisceração, lavados e retirados os seus conteúdos obtendo-se assim o conteúdo gástrico (CG) total dos quatro compartimentos.

Para a determinação do $\mathrm{pH}$ ruminal, uma alíquota do conteúdo do rúmen foi filtrada com gases e imediatamente o $\mathrm{pH}$ foi aferido (MORÁN et al., 2013). Para a identificação e quantificação de protozoários ciliados, o conteúdo ruminal foi filtrado e uma alíquota de $10 \mathrm{ml}$ de líquido ruminal foi transferida para frascos de vidros, com $10 \mathrm{ml} \mathrm{de}$ formaldeído a $30 \%$. As amostras permanecerem em repouso até o momento da contagem diferencial dos protozoários ciliados, a qual se baseou na técnica descrita por DEHORITY (2003).
Para avaliar o índice de ruminite, logo após a evisceração, os rúmens foram isolados dos outros compartimentos do estômago, abertos, lavados em água corrente e examinados. As papilas ruminais foram classificadas visualmente, conforme a incidência de lesões numa escala de escore de 0 a 10 , seguindo a metodologia proposta por BIGHAM \& MCMANUS (1975), em que cada ponto de escore representa $10 \%$ do rúmen comprometido. Foi considerada incidência de ruminite qualquer classificação acima de zero. Como é uma classificação visual e, portanto, subjetiva, a avaliação foi realizada por uma pessoa treinada.

Para a avaliação morfológica das papilas do rúmem, foi coletado um fragmento de aproximadamente $3 \mathrm{~cm}^{2}$ da região do saco cranial de cada rúmen e estes foram imediatamente imersos em frascos contendo solução de tampão fosfato e resfriados para preservar ao máximo as características biológicas. Foram avaliados: número de papilas $/ \mathrm{cm}^{2}$ presentes em cada fragmento, área média das papilas, \% área papilar e superfície total de absorção por $\mathrm{cm}^{2}$ de parede. O número total de papilas, em todo o fragmento, foi mensurado por três avaliadores e o número médio foi determinado para cada animal. Posteriormente, a base dos fragmentos e as doze papilas seccionadas na base, e estas foram estimadas através do programa de análise de imagens UTHSCSA Image Tool (RESENDE JÚNIOR et al., 2006).

O delineamento experimental utilizado foi o de blocos casualizados, com três tratamentos (MGI, MGM e MGU) e, para a formação dos blocos, foi levado em consideração o peso dos animais. Os dados foram avaliados pelo procedimento GLM do software SAS (SAS Inst. Inc., Cary, NC), com número de repetições desbalanceado. Os efeitos dos tratamentos foram avaliados por análise de variância e as médias dos tratamentos comparadas pelo teste de Tukey.

Os dados de $\mathrm{pH}$ de fezes foram analisados pelo procedimento Mixed do software SAS (SAS Inst. Inc., Cary, NC). Como os dados obtidos para ruminite não apresentam normalidade, foram analisados pelo procedimento NPAR1WAY do SAS (2003) e teste de Kruskall-Wallis. Foi considerada a tendência de valores de $\mathrm{P}$ de $5 \%$ a $10 \%$ de probabilidade.

\section{RESULTADOS E DISCUSSÃO}

Apenas nos primeiros quatorze dias do experimento os animais alimentados com MGU tiveram menor ingestão de matéria seca, acredita-se que os animais ainda se encontravam em adaptação 
nesse primeiro período e, portanto, apresentaram menor PVF ( $\mathrm{P}=0,0391)$ em comparação ao MGI. Foi observada uma probabilidade estatística de 0,0712 para maior ganho de peso vivo em animais alimentados com MGI.

BORGES et al. (2011) avaliaram dietas sem volumoso, sendo a fonte de fibra o milho grão, para cordeiros Texel confinados, e obtiveram ganhos de peso de $265 \mathrm{~g}$ a $305 \mathrm{~g}$ por dia, sendo neste trabalho descritos valores para o grão de milho inteiro de $360 \mathrm{~g}$ por dia, comprovando a eficiência da dieta em proporcionar alto desempenho de cordeiros confinados.

Neste trabalho, a conversão alimentar $(\mathrm{P}=0,11)$ e a eficiência alimentar $(\mathrm{P}=0,11)$ não foram influenciadas pelo processamento do grão de milho, o que indica que é possível a utilização de qualquer uma das três dietas avaliadas, devendo-se considerar o custo de produção, a disponibilidade de tecnologia e a oferta do produto no mercado (Tabela 2). A conversão alimentar ( $\mathrm{kg}$ de MS kg-1 peso vivo) dos cordeiros do estudo de BORGES et al. (2011), com dietas sem volumoso, foi de 3,52 e, neste projeto, de 3,43 para o tratamento MGI, portanto, muito próximo.

No presente estudo, não foi observado nenhum efeito de tratamento sobre a incidência ou severidade dos abscessos hepáticos. Todos os fígados dos animais foram classificados na escala 0 , o que caracteriza ausência de abscessos. BRENT (1976) descreveu a patologia de abscessos no fígado e sugeriu que ruminites e abscessos hepáticos são condições inseparáveis, por que permitem que os micro-organismos entrem na circulação porta $\mathrm{e}$ infectem o fígado. Não foi observada diferença entre os tratamentos $(\mathrm{P}=0,19)$ para o índice de ruminite (Tabela 3). Os valores obtidos foram baixos, não ultrapassando 0,9 pontos $(9 \%$ do rúmen comprometido com lesões). Uma explicação para isso seria o manejo alimentar adotado, uma vez que foi realizada a adaptação dos animais às dietas, com elevação gradual dos níveis de concentrado, evitando portanto a troca abrupta de nutrição.

Não foi observado efeito dos tratamentos sobre o número de papilas $\mathrm{cm}^{-2}$ de parede ruminal $(\mathrm{P}=0,3948)$, nem sobre a área média das papilas $(\mathrm{P}=0,1171)$, como descrito na tabela 3. Porém, foi observada maior $(\mathrm{P}=0,04)$ área papilar $(\% \mathrm{da}$ superfície de absorção) e uma tendência $(\mathrm{P}=0,06)$ de maior superfície de absorção $\mathrm{cm}^{-2}$ de parede ruminal, para o tratamento MGI. Esse resultado é contraditório em relação ao da literatura, uma vez que o processamento do grão de cereais proporciona um aumento no suprimento de carboidratos não fibrosos, aumentando a produção de AGCC, como o butirato e o propionato, que atuam direta e indiretamente na variação do tamanho papilar (OWENS et al., 1998; RESENDE JÚNIOR \& CRUZ, 2006).

Provavelmente, os processamentos do milho não ocasionaram mudanças significativas nas proporções dos ácidos graxos voláteis, uma vez que, na avaliação do epitélio do rúmen, não foi encontrada incidência de ruminite. Acreditase que a diferença encontrada, para área papilar e a tendência de maior superfície de absorção, possa ser explicada por outros fatores; tais como a ingestão de alimentos sólidos. $\mathrm{O}$ efeito da ingestão de alimentos sólidos sobre o crescimento ruminal depende, além dos produtos finais da fermentação, de outros fatores, como o estímulo à motilidade do órgão. Devido ao processo mastigatório dos ovinos

Tabela 2 - Média, erro-padrão da média (EPM) e probabilidade (P) das variáveis de peso vivo inicial (PVI), peso vivo final (PVF), ganho de peso vivo (GPV) ganho médio diário (GMD), ingestão de matéria seca (IMS) em kg/dia e em \% PV, conversão (CA) e eficiência alimentar (EA), em função das dietas experimentais.

\begin{tabular}{|c|c|c|c|c|c|}
\hline \multirow{2}{*}{ Variáveis } & \multirow[b]{2}{*}{ MGI } & \multirow[b]{2}{*}{ MGM } & \multirow[b]{2}{*}{ MGU } & \multirow{2}{*}{ EPM } & \multirow{2}{*}{$P$} \\
\hline & & & & & \\
\hline Número de animais & 8 & 6 & 8 & & \\
\hline PVI (kg) & 27,67 & 27,45 & 26,27 & 0,85 & 0,5334 \\
\hline PVF (kg) & $50,2^{\mathrm{a}}$ & $49,03^{\mathrm{ab}}$ & $44,89^{\mathrm{b}}$ & 1,09 & 0,0361 \\
\hline GPV (kg) & 22,58 & 21,58 & 18,62 & 0,76 & 0,0712 \\
\hline GMD (kg) & 0,36 & 0,34 & 0,30 & 0,01 & 0,0871 \\
\hline IMS, $\mathrm{kg} / \mathrm{dia}$ & 1,23 & 1,23 & 1,13 & 0,03 & 0,3768 \\
\hline IMS, \% PV & 3,13 & 3,22 & 3,16 & 0,06 & 0,8299 \\
\hline CA (kg IMS/kg ganho) & 3,43 & 3,66 & 3,87 & 0,10 & 0,1145 \\
\hline EA(kg ganho/kg IMS) & 0,29 & 0,27 & 0,26 & 0,01 & 0,1151 \\
\hline
\end{tabular}

Tratamentos: MGI: milho grão inteiro, MGM: milho grão moído, MGU: milho grão úmido. Médias seguidas de letras minúsculas distintas na mesma linha diferem entre si pelo teste de Tukey. 
Tabela 3 - Média, erro padrão da média (EPM), e probabilidade (P) das variáveis, índice de ruminite, morfologia da parede ruminal, conteúdo gástrico, $\mathrm{pH}$ ruminal e das fezes, em função das dietas experimentais.

\begin{tabular}{|c|c|c|c|c|c|}
\hline \multirow{2}{*}{ Variáveis } & & s experim & 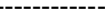 & \multirow{2}{*}{ EPM } & \multirow{2}{*}{$P$} \\
\hline & MGI & MGM & MGU & & \\
\hline Número de animais & 8 & 6 & 8 & & \\
\hline Superfície de absorção $\mathrm{cm}^{-2}$ de parede $\left(\mathrm{cm}^{2}\right)$ & 19,07 & 17,22 & 14,36 & 0,91 & 0,0595 \\
\hline Número de papilas $\mathrm{cm}^{-2}$ de parede & 45,75 & 37,57 & 45,12 & 2,50 & 0,3948 \\
\hline Área papilar (\% da superfície de absorção) & $95,06^{\mathrm{a}}$ & $94,31^{\mathrm{ab}}$ & $93,39^{\mathrm{b}}$ & 0,32 & 0,0443 \\
\hline Área media das papilas $\left(\mathrm{cm}^{2}\right)$ & 0,41 & 0,46 & 0,32 & 0,03 & 0,1171 \\
\hline Conteúdo gástrico $(\mathrm{kg})$ & $4,51^{\mathrm{a}}$ & $3,73^{\mathrm{ab}}$ & $3,36^{\mathrm{b}}$ & 0,19 & 0,0140 \\
\hline $\mathrm{pH}$ ruminal & $5,37^{b}$ & $6,62^{\mathrm{a}}$ & $6,63^{\mathrm{a}}$ & 0,15 & $<, 0001$ \\
\hline $\mathrm{pH}$ fezes & 7,35 & 6,94 & 7,45 & 0,10 & 0,1069 \\
\hline
\end{tabular}

Tratamentos: MGI: milho grão inteiro, MGM: milho grão moído, MGU: milho grão úmido.

Médias seguidas de letras minúsculas distintas na mesma linha diferem entre si pelo teste de Tukey.

ser bastante eficiente, os grãos inteiros consumidos foram reduzidos a partículas pequenas, semelhantes às dos grãos moídos.

Foi encontrada diferença $(\mathrm{P}=0,01)$ entre as dietas para o conteúdo gástrico (Tabela 3). $\mathrm{O}$ tratamento MGI, apresentou maior CG $(4,51 \mathrm{~kg}) \mathrm{em}$ relação ao MGU $(3,36 \mathrm{~kg})$, mas não diferiu do MGM $(3,73 \mathrm{~kg})$ e não foi observada diferença significativa entre os tratamentos MGM e MGU. Neste experimento, o tempo de jejum foi semelhante entre os tratamentos e a menor velocidade de passagem pelo rúmen do milho grão inteiro pelo estômago, em relação ao milho grão úmido, pode explicar, em parte, a diferença observada entre os resultados obtidos. O milho grão úmido tem a disgestibilidade mais fácil em relação ao milho seco e isso pode interferir no peso do conteúdo gástrico.

$\mathrm{O} \mathrm{pH}$ ruminal foi menor $(\mathrm{P}<0,0001)$ para MGI, em relação aos demais tratamentos, que não diferiram entre si. Segundo MÓRAN et al. (2012), valores médios de $\mathrm{pH}$ ruminal de 5,52 refletem acidose ruminal. No entanto, os animais que receberam MGI não apresentaram nenhum dos sintomas relacionados a esse distúrbio.

Os valores de $\mathrm{pH}$ ruminal variam de 5,5 a 6,2 quando a dieta possui uma maior proporção de concentrado e valores de $\mathrm{pH}$ de 6,2 a 7,0, quando a dieta é composta principalmente por volumoso (LIMA, et al., 2012). Um dos fatores fisiológicos que interferem na população microbiana do rumem é o $\mathrm{pH}$, sendo que os protozoários atuam no controle do $\mathrm{pH}$ do fluido ruminal, pois têm a capacidade de engolfar grânulos de amido em suspensão no conteúdo ruminal, sendo responsáveis por até $45 \%$ da atividade amilolítica no rúmen, e, portanto, sua população é maior em dietas de alto grão (DAYANI, et al., 2007; LIMA, et al., 2012).
Em relação aos gêneros de protozoários, o gênero majoritário foi o Entodinium, que alcançou $78,20 \%$ da população total. Os animais alimentados com MGM apresentaram maiores quantidades dos gêneros Entodinium e Epidinium e menores do gênero Eudiplodinium, em comparação aos alimentados com MGU. Para os outros gêneros, não foram encontradas diferenças entre essas duas formas de processamento (Tabela 4).

A utilização de milho grão processado na alimentação de cordeiros, aumentou a quantidade total dos gêneros de protozoários ciliados, em relação ao tratamento MGI $(\mathrm{P}<, 0001)$, em resposta à maior disponibilidade de substrato (amido) e seu melhor aproveitamento, o que possivelmente propiciou um melhor desenvolvimento microbiano, favorecendo a maior população de protozoários e o $\mathrm{pH}$. Os diferentes métodos de processamento de grãos melhoram a digestibilidade do amido, o que aumenta a fermentação ruminal e disponibiliza mais energia para microbiota ruminal e, consequentemente, maiores populações de protozoários (HUNTINGTON, 1997; HENRIQUE et al., 2007).

Os animais do tratamento com milho inteiro foram abatidos com maior peso vivo e apresentaram maior conteúdo gástrico, maior área de papila ruminal em relação à porcentagem da superfície de absorção, assim como menor $\mathrm{pH}$ ruminal e menor quantidade de protozoário, quando comparado com os animais alimentados com milho úmido e semelhantes aos cordeiros alimentados com milho moído. Essas informações, avaliadas em conjunto, indicam que a dieta de milho inteiro tem velocidade de degradação menor no rumem, e provavelmente com um perfil de ácidos graxos diferentes das demais dietas, mas que isso 
Tabela 4 - Média, erro padrão da média (EPM), e probabilidade $(\mathrm{P})$ do número de protozoários $\left(\mathrm{x} 10^{4} \mathrm{ml}^{-1}\right)$ ciliados do conteúdo ruminal de cordeiros alimentados com dietas de elevada proporção de concentrado.

\begin{tabular}{|c|c|c|c|c|c|}
\hline \multirow{2}{*}{ Protozoários } & & & & \multirow{2}{*}{ EPM } & \multirow{2}{*}{$P$} \\
\hline & MGI & MGM & MGU & & \\
\hline Número de animais & 8 & 6 & 8 & & \\
\hline Entodinium & $12,53^{\mathrm{c}}$ & $17,05^{\mathrm{a}}$ & $14,58^{\mathrm{b}}$ & 0,46 & $<, 0001$ \\
\hline Diplodinium & $0,58^{\mathrm{b}}$ & $0,88^{\mathrm{a}}$ & $0,99^{\mathrm{a}}$ & 0,05 & $<, 0001$ \\
\hline Epidinium & $0,61^{\mathrm{c}}$ & $1,02^{\mathrm{a}}$ & $0,86^{\mathrm{b}}$ & 0,04 & $<, 0001$ \\
\hline Isotricha & $0,73^{\mathrm{b}}$ & $0,97^{\mathrm{a}}$ & $1,00^{\mathrm{a}}$ & 0,04 & 0,0003 \\
\hline Dasytricha & $0,61^{\mathrm{b}}$ & $1,08^{\mathrm{a}}$ & $1,04^{\mathrm{a}}$ & 0,06 & $<, 0001$ \\
\hline Ostracodinium & $0,27^{\mathrm{b}}$ & $0,38^{\mathrm{a}}$ & $0,39^{\mathrm{a}}$ & 0,02 & 0,0009 \\
\hline Eudiplodinium & $0,25^{\mathrm{b}}$ & $0,31^{\mathrm{b}}$ & $0,35^{\mathrm{a}}$ & 0,02 & 0,0196 \\
\hline Total & $15,57^{\mathrm{c}}$ & $21,69^{\mathrm{a}}$ & $19,21^{\mathrm{b}}$ & 0,63 & $<, 0001$ \\
\hline
\end{tabular}

Tratamentos: MGI: milho grão inteiro, MGM: milho grão moído, MGU: milho grão úmido.

Médias seguidas de letras minúsculas distintas na mesma linha diferem entre si pelo teste de Tukey.

não prejudicou o desempenho do animal, sendo observado pelo peso vivo ao abate.

\section{CONCLUSÃO}

A utilização de dieta com milho grão inteiro resultou em maior peso vivo final, área papilar e maior conteúdo gástrico em relação à dieta com milho grão úmido. Ressalta-se a vantagem de usar o milho inteiro em relação aos demais pela facilidade de uso na propriedade, por não passar por nenhum processamento e consequentemente apresentar menor custo econômico.

\section{COMITÊ DE ÉTICA}

Universidade de São Paulo, Faculdade de Zootecnia e Engenharia de Alimentos. Comitê de Ética em Pesquisa - Área Animal. Processo USP número: 2011.1.929.74.6. Data de entrega: 21/07/2011. O projeto foi referendado pelo Comitê de Ética no dia 16 de agosto de 2011.

\section{REFERÊNCIAS}

BIGHAM, M.L.; McMANAUS, W.R. Whole wheat grain feeding of lambs. Effects of roughage and wheat grain mixtures. Australian Journal of Agriculture Research, v.26, p.1053-1062, 1975. Disponível em: <http://www.publish.csiro.au/?act=view file\&file id=AR9751053.pdf $>$. Acesso em: 11/02/2014. doi: 10.1071/AR9751053

BORGES, C.A.A. et al. Substituição de milho grão inteiro por aveia preta grão no desempenho de cordeiros confinados recebendo dietas com alto grão. Semina: Ciências Agrárias, v.32, supl.1, p.20112020, 2011. Disponível em: <http://dx.doi.org/10.5433/16790359.2011v32n4Sup1p2012>. Acesso em: 11/02/2014.

BRENT, B.E. Relationship of acidosis to other feedlot ailments Journal of Animal Science, v.43, p. 930-935, 1976. Disponível em: <https://www.animalsciencepublications.org/publications/ jas/abstracts/43/4/JAN0430040930>. Acesso em: 01/11/2013. doi:10.2134/jas1976.434930x.

BRINK, D.R et al. Severity of liver abscesses and efficiency of feed utilization of feedlot cattle. Journal of Animal Science, v.68, p.12011207, 1990. Disponível em: <https://www.animalsciencepublications. org/publications/jas/abstracts/68/5/1201?search-result=1>. Acesso em: 11/02/2015. doi: /1990.6851201x.

BROWN, M.S. et al. Adaptation of beef cattle to high-concentrate diets: performance and ruminal metabolism. Journal of Animal Science, v.84, (E.Suppl.), p.25-33, 2006. Disponível em: <https:// www.animalsciencepublications.org/publications/jas/articles/84/13 suppl/0840025 ?highlight=\&search-result=1>. Acesso em: 11/02/2015. doi: /2006.8413_supplE25x..

CAETANO, M. Efeito do processamento do milho e dos teores de fibra no desempenho de bovinos Nelore em terminação. 2012. 126f. Tese (Doutorado em Ciência Animal e Pastagens Escola Superior de Agricultura "Luiz de Queiroz", Universidade de São Paulo, SP.

DAYANI, O. et al. Effects of dietary whole cottonseed and crude protein level on rumen protozoal population and fermentation parameters. Small Ruminant Research, v.69, p.36-45, 2007. doi:10.1016/j.smallrumres.2005.12.007. Disponível em: $<$ http:// ac.els-cdn.com/S0921448805005043/1s2.0S0921448805005043 main.pdf? tid=f53eba06b20e11 e491350000aab0f6c\&acdnat $=14$ 23673984_2a4224a97461c75303b23db66efcc09c>. Acesso em: $01 / 10 / 201 \overline{3}$

DEHORITY, B.A. Rumen microbiology. Thrumpton: Nottingham University, 2003. 372p.

GOMIDE, C.A. et al. Influência da diferença cátion-aniônica da dieta sobre o balanço de cálcio, fósforo e magnésio em ovinos. Arquivo Brasileiro de Medicina Veterinária e Zootecnia, v.56, n.3, p.363-369, 2004. Disponível em: <http://dx.doi.org/10.1590/ S0102-09352004000300012>. Acesso em: 01/11/2013.

HENRIQUE, W. et al. Avaliação da silagem de grãos de milho úmido com diferentes volumosos para tourinhos em terminação. 
Desempenho e características de carcaça. Revista Brasileira de Zootecnia, v.36, n.1, p.183-190, 2007. Disponível em: $<$ http://dx.doi.org/10.1590/S1516-35982007000100022>. Acesso em 01/11/2013.

HUNTINGTON, G.B. Starch utilization by ruminants: from basics to the bunk. Journal of Animal Science, v.75, p.852-867, 1997. Disponível em: <https://www.animalsciencepublications. org/publications/jas/abstracts/75/3/852? search-result=1>. Acesso em 01/11/2013. doi: /1997.753852x

LIMA, M.E. et al. Alterações na população de protozoários ruminais, quantificados a partir da adaptação da técnica de Dehority, de ovinos submetidos a uma dieta de confinamento. Acta Scientia e Veterinariae, v.40, n.1, p.1019, 2012. Disponível em: $<$ http://www.ufrgs.br/actavet/40-1/PUB\%201019.pdf $>$. Acesso em $10 / 11 / 2013$.

MORÁN, L. et al. Metabolic acidosis corrected by including antioxidants in diets of fattening lambs. Small Ruminant Research, Small Ruminant Research, Volume 109, Issues 2-3, January 2013, Pages 133-135. Disponível em: <http://dx.doi. org/10.1016/j.smallrumres.2012.08.009>. Acesso em 05/01/2014.
OWENS, F.N. et al. Acidosis in cattle: a review. Journal of Animal Science, v.76, p.275-286, 1998. Disponível em: $<$ https:/www.animalsciencepublications.org/publications/jas/ abstracts/76/1/275? search-result=1>. Acesso em 11/11/2013. doi: $/ 1998.761275 x$

PASSINI, R. et al. Parâmetros de fermentação ruminal em bovinos alimentados com grãos de milho ou sorgo de alta umidade ensilados. Revista Brasileira de Zootecnia, v.32, n.5, p.12661274, 2003. Disponível em: <http://dx.doi.org/10.1590/S1516$35982003000500030>$. Acesso em 11/11/2013.

RESENDE JÚNIOR, J.C. et al. Effect of the feeding pattern on rumen wall morphology of cows and sheep. Brazilian Journal of Veterinary Research and Animal Science, v.43, n.4, p.526-536, 2006. Disponível em: <http://www.revistas.usp.br/bjvras/article/ view/26469/28252>. Acesso em 10/01/2014. doi: 10.1590/S141395962006000400013

STEELE, M.A. et al. Ruminal acidosis and the rapid onset of ruminal parakeratosis in a mature dairy cow: a case report. Acta Veterinaria Scandinavica, v.59, n.39, p.1-6. 2009. Disponível em: <http://www.actavetscand.com/content/51/1/39>. Acesso em 10/01/2014. doi:10.1186/1751-0147-51-39. 